\title{
Student Readiness to e-learning in Clinical Medicine. COVID Experience of Gynaecology Clerkship Students of Shifa College of Medicine
}

\author{
Gulshan Ara Saeed ${ }^{1}$, Tasneem Akhtar ${ }^{2}$, Hira Suleman ${ }^{3}$, Ahmad Sultan Zaheer ${ }^{4}$ \\ ${ }_{1,2,3}$ Shifa College of Medicine, Shifa Tameer e Millat university, Islamabad, Pakistan. \\ ${ }_{4}$ Volunteer Student. \\ Corresponding author. Email: gulshanzaheer@gmail.com
}

\begin{abstract}
PURPOSE: Undergraduate medical curriculum does not impart e-skills hence students learning outcomes may vary [1]. The use of exclusive e-learning during COVID has put forth the question "has targeted student learning been achieved?" As the educational environment in e-class has different dynamics, teaching strategies effective in classrooms may become irrelevant in online teaching and learning [2]. The purpose of this study was to identify the relationship between student readiness, motivation, and engagement in e-learning.

METHODS: To identify the relationship between student readiness to e-learning and their motivation and engagement in learning we used a validated questionnaire [3]: to assess the e-learning readiness of fourth and final year students of Shifa College of Medicine We used another feedback questionnaire to gather the COVID experience of these students' parents.

RESULTS: Multiple regression analysis showed that student's e-readiness was a strong predictor of students' engagement and motivation in e-learning. The student who scored high on computer skills had a better perception of the e-learning climate.

Parental feedback brought forward the issue of all institutions conducting their interactive teaching sessions at the same time leading to problems in the provision of logistics and interruption-free educational environment for more than one sibling creating a lot of parental stress.

CONCLUSION: Medical educationists need to incorporate technology-based learning as an integral part of an undergraduate medical curriculum. They have to focus on e-learning climate dynamics as they vary from on-campus learning and affect student engagement in e-learning.

Keywords: "active learning", "educational activity", "motivation".
\end{abstract}

\section{INTRODUCTION}

Worldwide, the undergraduate medical curriculum is designed with the intent of face-to-face teaching-learning [1]. There are many inbuilt online components but with the COVID pandemic, medical educationists were forced to adopt technologyenhanced learning. Online, e-learning and technologyenhanced learning can be simply described as the "use of electronic technology and media to deliver, support and enhance teaching, learning. It involves communication between learner and teacher utilizing online content"[2]. Although technology-enhanced learning has been researched for delivering and assessment of knowledge component3, the skill and attitudes part of the online undergraduate medical teaching and learning online has always challenged for educationists [4]. From a training perspective, for online teaching and learning of undergraduate medical competencies, comprehensive research is not available[5]. at the onset of the COVID pandemic, neither the undergraduate medical students were primed for any such e-component in the curriculum nor were the faculty trained for online teaching [3]. Undergraduate medical students and faculty have frequent exposure to online videos and lectures but esmall group, e-problem based, e-case oriented discussions have lagged utility evaluation [6].

The undergraduate medical curriculum requires the students of years four and five to have their assessment-based on clinical learning. With the COVID outbreak, these clerkships were converted to online courses which are generally perceived as inferior to face-to-face learning in terms of low on motivation and program retention [7]. The faculty and administration had strong concerns regarding students achieving the required competencies. Among other things, even the learning environment is not congruent in online and on-campus learning. Medical 
educationists, therefore, have to realign the undergraduate medical curriculum to be safely delivered on-campus and online. They have to ensure that the competencies planned are best taught with the software or technology aimed for their delivery. Each software and interface has some requirements to successfully deliver specific curricular content [8]. The students and the faculty have to be trained regarding the strengths and limitations of newer or modified technology-based learning systems to ensure the best fit for the required teaching and learning content[9].

Students and their self-efficacy is crucial for their effective learning[10]. Research shows that learning environments allowing a higher degree of learner autonomy results in greater learner motivation and better learning[11]. The learning environment involves much more than the teacher and the learner. The learning environment has been perceived to be quite different in online sessions by learners and faculty[2]. A lot of noise and voice distortion may occur if all participants open their microphones simultaneously. Similarly, an audio time lag is experienced during interactive sessions.

Research is available on the effect of online teaching and learning from the student and teacher perspective[12]. There are other stakeholders in the equation. One of them is the student's parents. With the advent of COVID, the parents were faced with the dual task of providing their children with emotional support for their anxieties and a secure educational environment at home. The online learning climate is an important determinant of student learning. The climate of learning refers to "social, emotional and physical conditions under which one acquires knowledge". In the COVID pandemic as the students were forced to continue their learning from their home environment, parental responsibility to provide them a good e-climate became more pronounced.

This study aims to determine the correlation between student readiness of e-learning of clinical medicine (obstetrics and gynecology) during COVID and their motivation for e-learning sessions and perception of e-educational climate. The study provides an insight into the missing component of parental support to ensure student learning.

\section{MATERIAL AND METHODS}

The five-year undergraduate medical program at Shifa College of Medicine provides clinical clerkships in years four and five. Obstetrics and gynecology for the undergraduate medical program are taught as a 4week long module in year four and a 9-week long module in year five with the students undertaking the exit exam for obstetrics and gynecology in year five. The curriculum is planned for face-to-face delivery to maximize the attainment of desired competencies of knowledge, skill, and attitudes in the students. With the onset of the COVID pandemic, the obstetrics and gynecology faculty members worked very hard to convert their clerkship program into an online distance learning course. The curriculum competencies of knowledge, skill, and attitude were realigned to enable student e-learning. The modes of information transfer were e-interactive lectures, e-small group discussions, e-case based discussions, interaction with actual, standardized, and simulated patients through telemedicine. Zoom, Google Classroom, and Google Meet were used for e-teaching. Pre and post-test and formative assessments were done through Socrative. Group tasks were done through the use of breakout rooms and Whatsapp groups. Videos of various skills were uploaded and discussed. Other activities included Pre and post discussion quizzes with feedback. Formative OSCE with standardized patients was done. Students were asked to present cases and provide evidence-based management options.

This survey was undertaken a few days after the start of e-teaching to allow students to provide an accurate measure of their readiness. We used a valid and reliable 32 item questionnaire 13 to assess the students' readiness to e-learning in our fourth and final year students at Shifa College of Medicine, Cronbachgynecologyuestionnaire was 0.98 . The aim was to assess student readiness to learn the whole obstetrics and gynaecology curriculum through elearning and to assess the student feedback regarding the learning environment self-learning are had 5 main, components (operating systems, internet self-efficacy, online communication, self- learning, learner control and motivation). Each component comprised of multiple questions to be answered on the Likert scale (1-not at all, 7-completely). The first component regarding operating system comprised of 5 questions. The second component on internet e-self- efficacy had 4 questions, online communication had 5, e-selflearning had 8 , and learner control had 3 while motivation had 7 questions. For each component of the questionnaire, the maximum and minimum score possible was calculated separately and a median was assigned. Independent $t$ test was applied to ascertain relationship between students' e-operations, internet efficacy, online communication, and self-learning and learner control scores to their e-learning motivation, eclimate perception, and anxiety regarding assessments.

The second part of the study was parental feedback on the COVID experience. Parents were requested to voluntarily reply to an 11-question survey. The survey was validated by 4 experienced medical educationists. The language appropriation was done by piloting it on 10 volunteers with secondary education. 
The survey was approved by the institutional review board and the participants were asked for electronic consent. Participation in the survey was voluntary. The Google survey form was distributed to 220 undergraduate medical students of the fourth and final year of Shifa College of Medicine of which 199 responses were received - indicating a response rate of
89 percent. For maximum response, the students were initially informed through Whatsapp groups regarding the survey. One week later the link of Google forms was shared with them. One week after sharing the link they were sent a soft reminder for completion. A total of 3 weeks were given for filling the form.

TABLE 1 E-learning readiness components

\begin{tabular}{|c|c|c|c|c|c|}
\hline $\begin{array}{l}\text { E-READINESS } \\
\text { COMPONENTS }\end{array}$ & $\begin{array}{l}\text { Mean } \\
\text { score } \\
\text { (S.D ratio) }\end{array}$ & $\begin{array}{l}\text { Correlation to } \\
\text { E-learning } \\
\text { motivation }\end{array}$ & $\begin{array}{l}\text { Correlation to } \\
\text { the anxiety of } \\
\text { E-written exam }\end{array}$ & $\begin{array}{l}\text { Correlation to } \\
\text { the anxiety of } \\
\text { E-OSCE exam }\end{array}$ & $\begin{array}{l}\text { Correlation to a } \\
\text { positive } \\
\text { perception of the } \\
\text { E-learning } \\
\text { environment }\end{array}$ \\
\hline $\begin{array}{l}\text { Operational } \\
\text { readiness }\end{array}$ & $5.46(1.56)$ & 0.584 & 0.151 & 0.272 & 0.183 \\
\hline P-value & & 0.000 & 0.020 & 0.000 & 0.006 \\
\hline $\begin{array}{l}\text { Internet self- } \\
\text { efficacy }\end{array}$ & $5.66(1.48)$ & 0.572 & 0.172 & 0.306 & 0.261 \\
\hline$P$ value & & 0.000 & 0.010 & 0.000 & 0.000 \\
\hline $\begin{array}{l}\text { Online } \\
\text { communication }\end{array}$ & $5.27(1.55)$ & 0.767 & 0.224 & 0.334 & 0.318 \\
\hline$P$ value & & 0.000 & 0.001 & 0.000 & 0.000 \\
\hline $\begin{array}{l}\text { E-learning self- } \\
\text { efficacy }\end{array}$ & $5.24(1.50)$ & 0.731 & 0.250 & 0.377 & 0.267 \\
\hline$P$ value & & 0.000 & 0.000 & 0.000 & 0.000 \\
\hline $\begin{array}{l}\text { Learner control of } \\
\text { e- learning }\end{array}$ & $5.26(1.51)$ & 0.780 & 0.213 & 0.383 & 0.273 \\
\hline$P$ value & & 0.000 & 0.002 & 0.000 & 0.000 \\
\hline
\end{tabular}

\section{RESULTS}

The survey data was entered and analyzed quantitatively in SPSS 16 . There were $53.2 \%$ female (106) and $46.7 \%$ male ( $n=93)$ students. The various components of the e-readiness questionnaire were calculated separately. Multiple Regressions were employed which showed a positive predictive effect of e-readiness and its components: motivation during e-

The parents were asked to mark their concerns regarding internet, electricity, and e-gadget availability. Twenty-six percent of parents agreed that the availability of dependable un-interrupted internet and twenty-five agreed un-interrupted electric supply sessions and positive perception of e-learning climate. Multiple regression of operational readiness to learning motivation was (Pearson $\mathrm{r}=0.584, \mathrm{P}=0.000$ ) and to e-learning climate perception (Pearson $\mathrm{r}=0.183$, $\mathrm{P}=0.000)$. However operational readiness to student anxiety regarding written assessment (Pearson $\mathrm{r}=0.151, \mathrm{P}=0.010$ and clinical assessment (Pearson $\mathrm{r}=0.272, \mathrm{P}=0.000$ ). (Table I).

was a source of stress. Although $47.7 \%$ had no issues regarding the availability of e-gadgets, many parents said that they had more than two kids. With the onset of COVID, all teaching shifted to online, and mainly time schedule between 8:00 hours to $15: 00$ was 
utilized. Parents faced a lot of stress and $24 \%$ of parents had trouble arranging e-learning resources. Sixty-four percent of parents were satisfied with the elearning process and were happy that safe learning options during the pandemic were utilized. However, $68 \%$ wanted the college administration and faculty to take parental feedback before undertaking a decision regarding medical students, and $63 \%$ of parents had strong apprehensions regarding COVID exposure of students with the resumption of on-campus activities.

\section{DISCUSSION}

We used a validated and reliable scale for the measurement of student readiness for e-learning. The intention was to see how student perceived their readiness to learn clinical competencies in an online format. These students had no formal training in elearning as the undergraduate medical curriculum at Shifa was designed for on-campus and face-to-face delivery. However, in year three of their program, these students undertake a research proposal writing with the literature search. With the advent of COVID, a sudden flip was encountered as all faculty and students were forced to teach and learn online3.

In our study, we saw that the fourth and final year students who had planned to study their obstetrics and gynecology course in the workplace showed varying degrees of readiness to e-learning. The results of our study showed that learner self-efficacy and motivation to learn were directly proportional to their readiness for e-learning. Hence in our study fourth and final year students who scored high on operational skills in using the internet were more motivated to discuss and interact in e-classrooms. However, exam anxiety for both written and clinical assessments was high among students as they felt lacking workplace exposure.

Regression scores showed that independent variables of e-readiness had a significant $(\mathrm{P}=0.000)$ positive effect on the student perception of the e-learning environment as helpful or conducive for their learning objectives. International literature supports the use of technology-enhanced learning as a means of delivering undergraduate course content in the COVID pandemic [14]. Costello et al have also discussed that students well trained in online sessions had a better experience of online learning [12].

The students of the fourth and final year who scored higher than the median score in self e-learning and learner control showed a higher rating of the elearning environment. They were of the view that online sessions combined "safety" and "learning" which was best possible during a pandemic. They showed greater satisfaction with meeting the course objectives. Other studies also show that with greater readiness for e-learning students are more involved and perform better in e-learning sessions and assessments[15]. However, these undergraduate medical students reported feeling a void in their clinical experience. The workplace climate and the non-verbal communication in their interaction with patients and teachers were suddenly removed from their learning experience. They were of the opinion that the medical curriculum never overtly emphasized e-learning and e-communication skills and that the elearning interface blocked the transfer of emotions and attitudes to a certain extent. These views were shared in international studies where students experienced elearning as different from on campus[4].

The students faced a lot of stress due to a variety of reasons. Firstly the pandemic was very sudden and many students or their family members fell-prey to the illness. Secondly, the transition to e-learning was very sudden and time wasn't provided for acclimatization to e-learning. Thirdly and perhaps more importantly, the curriculum was not originally developed for eteaching. In this regard, we inquired from the parents how their experience of this home-based learning was. The parents faced stress because the internet service would falter as all schools, colleges, and universities were utilizing the same hours for their teaching sessions. The net service would become slow resulting in repeated disconnections. Zoom service used by most teachers would disconnect after 40 minutes and would need re-joining. Few parents had issues with arranging multiple e-gadgets for their children as online assignments needed complex functions not easily performed without a laptop.

Parents agreed that although students at this stage are "adult learners" and are responsible for their own learning, but during the pandemic, all boarders and day scholars went home, and learning became homebased. Parents were of the opinion that in the COVID scenario the "parental input" was vital for the faculty and the institutional administration as the "learning" was shifted to an environment with varying dynamics. The majority was of the opinion that better results could have been achieved if input from "parents" had been part of the e-curriculum delivery planning by the institute.

In general, the parents were satisfied with the online teaching and learning however they were of the opinion that home learning environments have many distractions and the e-teaching sessions have to be much more robust in involving students to overcome this. This view was shared by students as they accepted that they engaged in social networking and gaming during e-learning sessions. Nine percent said that they indulged in gaming in-between sessions as online lectures became boring. Most of the $22 \%$ who said that they indulged in social networking during sessions said that they were trying to assist friends having internet issues. 
Many parents had anxiety regarding students going back to on-campus learning as the COVID pandemic is far from over. All countries are still on a high alert devoting all available resources for the treatment of cases, preventing community infection, and health care worker protection[16]. Therefore, the problem of students returns to clinics and provision of personal protective equipment and COVID safe environment is still not being targeted. However, many parents and students felt that it was medical student's duty to perform and assist in health care. These views were in agreement with international data where students are continuing clerkships or are assisting in providing medical care[17,10].

Further research has to be done to evaluate which learning styles and study habits complement elearning to help students learn effectively through a technology-based interface[18].

Most importantly the definition of "success", "course completion" and "program objectives achieved" of on-campus curriculum delivery may vary in online curriculum delivery [18].

Students when experienced online activities felt a major issue in the learning environment and the lack of non-verbal feedback. The students in our study complained of 'losing their touch' of clinical proficiency and competence of good communication skills.

\section{CONCLUSION}

It was a major lapse on part of the policymakers and institutions not to take into account student readiness to e-learning and parental input regarding resources. Time and resources spent on student training and acclimatization to the various e-learning strategies would have helped achieve better learning outcomes. As the pandemic continues to have effects worldwide, educators should take feedback from all stakeholders on how to best tailor their programs for improved student involvement and provision of a better e-learning environment.

\section{AUTHORS' CONTRIBUTIONS}

Dr. Gulshan Ara Saeed: Conceptualization, planning, manuscript writing, data analysis review

Dr. Tasneem Akhtar: Manuscript writing, Literature review, proofreading

Dr. Hira Suleman: Manuscript proofreading, data collection

Mr. Ahmad Sultan Zaheer: Developing google document, data collection, data entry, data analysis.

\section{ACKNOWLEDGMENTS}

Professor Dr. Raheela Yasmeen, Riphah international university for her support and guidance. Dr. Alem Farid for contributing to this research by allowing us the use of his questionnaire.

Dr Jawad Zaka Khan for proof reading and grammatical corrections.

\section{REFERENCES}

[1] Wong RY, Roberts JM. Real time curriculum map for internal medicine residency. $B M C$ Med Educ. 2007;7(February 2007). doi:10.1186/1472-6920-7-42

[2] Howlett D, Vincent T, Gainsborough N, et al. Integration of a case-based online module into an undergraduate curriculum: What is involved and is it effective? E-Learning. 2009;6(4):372-384.

doi:10.2304/elea.2009.6.4.372

[3] Sandhu P, de Wolf M. The impact of COVID19 on the undergraduate medical curriculum. Med Educ Online. 2020;25(1):4-5. doi:10.1080/10872981.2020.1764740

[4] Wolff M, Hammoud M, Santen S, Deiorio N, Fix M. Coaching in undergraduate medical education: a national survey. Med Educ Online. 2020;25(1). doi:10.1080/10872981.2019.1699765

[5] Wynia MK, Papadakis MA, Sullivan WM, Hafferty FW. More than a list of values and desired behaviors: A foundational understanding of medical professionalism. Acad Med. 2014;89(5):712-714. doi:10.1097/ACM.0000000000000212

[6] Mooney GA, Bligh JG. Information technology in medical education: Current and future applications. Postgrad Med J. 1997;73(865):701-704.

doi:10.1136/pgmj.73.865.701

[7] Watkins Ryan, Leigh Doug TD. Assessing Readiness for E-Learning. Perform Improv Quarterly, 17(4) pp 66-79. 2004;17(4):66-79. doi:10.1111/j.1937-8327.2004.tb00321.x 
[8] Oskvarek J, Braunstein S, Farnan J, et al. A targeted needs assessment. 2017;31(3):529532. doi:10.1007/s13187-015-08762.Medical

[9] Larocque N, Lee SY, Monteiro S, Finlay K. Reform of a Senior Medical Student Radiology Elective Using a Needs Assessment. Can Assoc Radiol J. 2018;69(3):253-259.

doi:10.1016/j.carj.2018.01.005

[10] Menon A, Klein EJ, Kollars K, Kleinhenz ALW. Medical Students Are Not Essential Workers: Examining Institutional Responsibility During the COVID-19 Pandemic. Acad Med. 2020;95(8):1149-1151. doi:10.1097/ACM.0000000000003478

[11] Dray BJ, Lowenthal PR, Miszkiewicz MJ, Ruiz-Primo MA, Marczynski K. Developing an instrument to assess student readiness for online learning: A validation study. Distance Educ. 2011;32(1):29-47. doi:10.1080/01587919.2011.565496

[12] Costello E, Corcoran M, Barnett JS, et al. Information and communication technology to facilitate learning for students in the health professions: Current uses, gaps, and future directions. J Asynchronous Learn Netw. 2014;18(4):1-18. doi:10.24059/olj.v18i4.512

[13] Alem F, Plaisent M, Zuccaro C, Bernard P. Measuring e-Learning Readiness Concept: Scale Development and Validation Using Structural Equation Modeling. Int $J \quad e$ Education, e-Business, e-Management $e$ Learning. 2016;6(4):193-207. doi:10.17706/ijeeee.2016.6.4.193-207

[14] Kim SM, Park SG, Jee YK, Song IH. Perception and attitudes of medical students on clinical clerkship in the era of the Coronavirus Disease 2019 pandemic. Med Educ Online. 2020;25(1):1809929. doi:10.1080/10872981.2020.1809929

[15] Kühbeck F, Berberat PO, Engelhardt S, Sarikas A. Correlation of online assessment parameters with summative exam performance in undergraduate medical education of pharmacology: a prospective cohort study. BMC Med Educ. 2019;19(1):1-9. doi:10.1186/s12909-019-1814-5

[16] Ripp J, Peccoralo L, Charney D. Attending to the Emotional Well-Being of the Health Care Workforce in a New York City Health System During the COVID-19 Pandemic. Acad Med. 2020;95(8):1136-1139. doi:10.1097/ACM.0000000000003414

[17] Miller DG, Pierson L, Doernberg S. The Role of Medical Students During the COVID-19 Pandemic. Ann Intern Med. 2020;173(2):145146. doi:10.7326/M20-1281

[18] Cooper MD. Towards a model of safety culture. Saf Sci. 2000;36(2):111-136. doi:10.1016/S0925-7535(00)00035-7

[19] Al-Sowygh ZH. Academic distress, perceived stress and coping strategies among dental students in Saudi Arabia. Saudi Dent J. 2013;25(3):97-105. doi:10.1016/J.SDENTJ.2013.05.002 